\title{
Re-infrastructuring for eHealth: dealing with turns in infrastructure development
}

\author{
Miria Grisot, \\ Department of Informatics, University of Oslo, Norway \\ miriag@ifi.uio.no,
}

Gaustadalléen 23 B, N-0373 Oslo, Norway

Tlf. (+47) 228524 10, fax (+47) 228524

Polyxeni Vassilakopoulou

Department of Information Systems, University of Agder, Norway

polyxenv@uia.no,

Gimlemoen 25, 4630 Kristiansand S, Norway

Tlf. (+47) 38142418 


\begin{abstract}
In this paper, we examine infrastructuring in the context of developing national, public eHealth services in Norway. Specifically, we analyze the work of a project team engaged in the design and development of new web-based capabilities for communication between citizens and primary healthcare practitioners. We frame the case as a study of re-infrastructuring to signify a particular occasion of infrastructuring that entails facilitating a new logic within established social and technological networks. To make sense of the particularities of re-infrastructuring, we draw from research in infrastructure studies which considers embeddedness as a resource in infrastructure evolution. We analyze how actors worked to re-infrastructure through adapting primary care information systems, information flows and representations of patient data. Our findings show how the work of re-infrastructuring revolves around addressing two key design concerns: a) bringing novelty without being trapped in the existing arrangements or harming what is in place, $b$ ) bringing changes that are within a specific direction although they happen through distributed decision taking.
\end{abstract}

Keywords: design, eHealth, embeddedness, information infrastructure, infrastructuring.

\title{
1. Introduction
}

The study of information infrastructures has instigated a type of research which is radically different from traditional studies of self-contained informatics' applications destined for specific work settings and situations of use (Monteiro et al. 2013). Infrastructure research is linked to a shift of focus towards sociotechnical arrangements where "technical, political, legal, and/or social innovations link previously separate, heterogeneous systems to form more powerful and far reaching networks" (Edwards et al. 2009, p. 369). The emergence of infrastructures is not only a question of purposeful design, nor is it just 'happening' without some intentionality involved; it is primarily an open process with many interdependencies that need to be dealt with. Understanding how infrastructures emerge and evolve has been one of the core focuses of infrastructure research in the field of CSCW.

Recently, attention has been given to a processual perspective on infrastructures that aims to foreground the design activities of infrastructures in-the-making. Research shows how the design work to infrastructure is not confined to a delimited design phase but unfolds over long periods, in a constant 'becoming' mode where the boundaries between design and use are blurred (Karasti and Syrjänen 2004). This view exposes the work needed in order to ensure that a well-working infrastructure is in place all the time facilitating productive relationships among people, organizations and technologies (Karasti et al. 2010; Pipek and Wulf 2009). Adding to this body of work we argue that it is important to develop a better understanding of the specific occasions for infrastructuring in the life of infrastructures. For instance, intervening in an existing infrastructure requires specific design practices which should take into account the maturity of the infrastructure at hand. Infrastructures result from cumulative processes over long periods of time (Pollock and Williams 2010). Thus, intervening in the early stages or on a well-established infrastructure means engaging with different design practices and addressing 
different design concerns. In this paper we study one process - which we describe as reinfrastructuring - where an existing infrastructure is further developed according to new logics and directions. We want to understand the work entailed in such an engagement with an already mature infrastructure.

Empirically, we examine the collaborative effort to create public patient-oriented eHealth services in Norway. Norway has a well-developed information infrastructure in the healthcare sector where a secure network connects all health providers since 2004. Hospitals, General Practitioner (GP) offices and nursing homes have Electronic Patient Record (EPR) systems and exchange standard electronic messages (e.g. referrals, discharge letters, prescriptions). At the time of the study, the Norwegian Government engaged in a new initiative to further develop the services offered by developing eHealth services for citizens. In this effort, the Norwegian Government plays many roles: initiator, investor, coordinator and creator. Norway has seen large investments on IT in the health sector over many years. From the early 90s IT strategies for the health sector have been defined. Over the years, large investments have been made, and the plans foresee large investments over many years in the future (Norwegian Ministry of Health and Care Services 2007, 2012, 2014). There is a coherent political agenda at high level - strategy documents - guiding the process. However, there are also many uncertainties. While the Government issued a long-term strategy, its realization is subject to shifting politics, prioritization logics and yearly budgeting schemes. Furthermore, there are multiple actors engaged with different identities and interests. While most of the existing information infrastructure is publicly owned, its various components are subject to different policies of development and use.

We have studied the work of re-infrastructuring by following the activities undertaken by a team within a governmental Agency which received the mandate to put in place eHealth services. Specifically, we have studied the process from the perspective of a project creating eHealth services to support the interactions between GPs and patients such as booking of health appointments, exchange of messages, access to personal health information or tests results. This shift towards the patient entails a reorientation and expansion of the infrastructure that is already in place which has been configured around the communication and information needs of health providers. We followed the project for more than two years from its initiation in 2013, to the start of the piloting phase. Our study focused on the unfolding of events and design decisions over time and on the rearrangement of sociotechnical interdependencies and relations. Of particular concern is how parts of the existing health information infrastructure get re-oriented, what work this entails, and how an embedded infrastructure in use can be re-purposed. Our study addresses the following research question: how can novelty be introduced to an established infrastructure to facilitate new logics and what work does this entail? In addressing the research question our aim to advance the current processual understanding of infrastructures by examining a specific occasion of infrastructuring.

The rest of the paper is structured as follows. In the next section, we draw from the literature and present theoretical conceptualizations that inform our research. This is followed by a presentation of the method we employed for conducting the study, and by a presentation of the empirical case and its analysis. We then discuss our findings and conclude our study. 


\section{Theoretical Background}

\subsection{Infrastructure evolution and change processes}

The term infrastructure is frequently used to indicate large networks of digital technologies, such as the Internet. These networks have the characteristic of being heterogeneous and they are often formed for supporting distributed collaborative practices by connecting over time different systems in a patchwork-like configuration (Ellingsen and Monteiro 2003; Hepsø et al. 2009). In addition to being heterogeneous and durable, infrastructures are also relational. An infrastructure works 'in between' and supports the work of multiple user groups often with diverging interests and priorities. Drawing on the work by Star (Bowker and Star 1999; Star and Ruhleder 1996) a significant body of research has examined the challenges of dealing with infrastructures as relational objects. For instance, prior research has focused on the difficulties of implementing approaches for data sharing (e.g. Baker and Millerand 2010; Ribes and Bowker 2009; Zimmerman 2008), on the challenges of standardization for collaborating across contexts and across local and global levels (e.g. Bjørn and Kensing 2013; Ellingsen and Monteiro 2006; Rolland and Monteiro 2002), and on how, overall, sociotechnical negotiations shape the evolution of infrastructures that are generative while standardized (Grisot and Vassilakopoulou 2013).

Another core characteristic defining infrastructures is their relation to the existing installed base. Star and Ruhleder describe it as follows: "infrastructure does not grow de novo: it wrestles with the 'inertia of the installed base' and inherits strengths and limitations from that base." (Star and Ruhleder 1996, p. 113). The notion of installed base refers in general to the number of installations or products sold. The size of the installed base and existence of complementary products may, through self-reinforcing growth mechanisms, determine success or failure in the market (see e.g. Farrell and Saloner 1986; Schilling 1999). However, in Information Infrastructure studies the notion of installed base has a broader meaning as it encompasses 'all that is there', including the existing work practices, tools and established division of labour, the legal and professional regulations in place, and so on (see e.g. Hanseth and Monteiro 1998).

Research has examined how infrastructures evolve. Studies of research infrastructures (e.g. Ribes and Polk 2014), health information infrastructures (e.g. Ellingsen and Monteiro 2003), and the Internet (e.g. Hanseth and Lyytinen 2010) all point to the complexity of infrastructure evolution. For instance, changing one element can have unforeseen effects throughout the whole infrastructural arrangement (Anderson et al. 2008; Hanseth et al. 2006; Pollock and Williams 2010). Change processes take place along multiple temporal scales where both change interventions and support to the daily running of the infrastructure have to be performed (Karasti et al. 2010). Moreover, infrastructure development is a visionary and political process with a moving target. It deals with an extended time span, as infrastructures are designed today to address future and unpredictable needs of users (Ribes and Finholt 2009). In addition, diverse and often conflicting interests shape their evolution (Bowker et al. 2009). Infrastructure development requires dealing with a process where clusters of artefacts and practices become more tightly coupled (Bossen and Markussen 2010) and novel developments get assimilated within everyday practices (Grisot and Vassilakopoulou 2011). The forming of infrastructures 
has a significant impact to collaborative practices connecting, influencing and creating entirely new ones (Ellingsen and Røed 2010; Hanseth and Lundberg 2001). Furthermore, research has examined how the existing installed base shapes infrastructure evolution (e.g. Hanseth and Monteiro 1998; Star and Ruhleder 1996) and suggested the concept of installed base cultivation to address change in an incremental and gradual manner (Ciborra 1997; Grisot et al. 2014; Hanseth and Aanestad 2003). The installed base is both enabling and constraining the evolution of infrastructures (Aanestad et al. 2017; Bietz et al. 2010; Grisot and Vassilakopoulou 2015a).

The evolution of infrastructures happens in different moments. Edwards et al. (2007) argue that there are two crucial moments in the history of infrastructures: the gateway phase and a phase of ongoing adjustment. In the gateway phase, previously separate entities - political, technical, legal, social - are linked. In the second phase, infrastructures "adapt to, reshape, or even internalize elements of their environment in the process of growth and entrenchment". This process of continuous adjustments can be driven by different logics and may also include 'jumps and turns'. In some cases, the introduction of novel technologies expands the existing infrastructure. The introduction of new collaboration and coordination tools for supporting the development of new communities of users (Zimmerman and Finholt 2007) or for expanding the reach and scope of collaboration within existing communities (de la Flor et al. 2010) are examples of such expansion. Differently, an infrastructure may evolve driven by scaling efforts (e.g. Monteiro 1998). Infrastructures also evolve through the ongoing handling of issues related to maintenance and repair (Jackson 2014; Jackson et al. 2012). Overall these different adjustments in the life of an infrastructure are never mere technical development. As infrastructures are sociotechnical, their development is characterized by political and negotiation processes (e.g. Sahay et al. 2009).

Adding to this body of literature we want to examine yet another type of adjustment in the evolutionary trajectory of infrastructures. The case examined in this paper investigates the work entailed in re-orienting an existing infrastructure according to new logics and directions. Specifically, our research explores how a team engaged with the design and development of novel eHealth services had to turn existing infrastructural arrangements from being configured around the communication and information needs of health providers, to being configured to serve the information and communication needs of patients. In the next section we suggest to conceptualize this turn in the life of an infrastructure as a process of re-infrastructuring.

\subsection{Infrastructuring and re-infrastructuring}

The studies that adopt an infrastructure perspective have a wide temporal and spatial framing reflecting the continuity of the processes that lead to their ever-increasing embeddedness and their growing scope (Star and Ruhleder 1996). Infrastructure has come to mean those resources and services — whether human, technical or sociotechnical — that enable, support, and shape activity (Ribes and Polk 2014). Infrastructure is always a social and political matter as much as it is a technical one. The everyday experience of infrastructure is of a 'boring background process' operating smoothly unless breakdowns happen (Star 1999). Actually, making an infrastructure visible means attending to the ways the infrastructure becomes someone's work or problem (Star 1999). In this view, infrastructure is best studied not as interlinked pieces of 
hardware or information processing capabilities, but rather as a process of infrastructuring, where sociotechnical relations are formed and maintained. A process view exposes how an infrastructure comes into existence in relation to organized 'technical, material and knowledge interventions' and through 'infrastructural work' (Edwards 2003; Star and Ruhleder 1996). Karasti and Baker (2004) use infrastructuring to refer to the ongoing process of creating infrastructures. Overall, infrastructuring entails the installation of a certain order through a process by which practices and artefacts become parts of social and technological networks (Bossen and Markussen 2010). Obviously, design activities are central to infrastructuring. Infrastructure literature has questioned the traditional understanding of design activities and showed how designing to infrastructure requires balancing different views and coordinate rhythms and trajectories of various participants (Karasti et al. 2010; Neumann and Star 1996; Pipek and Wulf 2009; Ribes and Finholt 2009).

When re-infrastructuring takes place, additional challenges emerge. Design initiatives that aim to re-orient infrastructures towards new logics and directions have to rework well-established connections ensuring a smooth transition to a novel envisioned configuration. We argue that re-infrastructuring is a special type of engagement with a mature infrastructure during a turn in its life which happens when strategically mandated adjustments to existing arrangements are pursued. In such circumstances, the activities of those involved in infrastructuring, are focused in maintaining the embeddedness of the established infrastructure while renegotiating the connections that make embeddedness possible. To make sense of the particularities of reinfrastructuring, we draw from research which has examined the embeddedness of infrastructures. Embeddedness refers to the way infrastructures are 'sunk' into other structures, social arrangements and technologies (Star and Ruhleder 1996). When an infrastructure is embedded into existing practices and social arrangements it becomes transparent and taken for granted. It becomes part of the everyday work. One fundamental insight from CSCW studies is the recognition of how technology is intimately intertwined with organizational structures and work practices. For instance, Berg and Winthereik describe the historical evolution of the patient record over the last century related to the organizational development of hospitals and the professional development of the medical and other health professions (Berg and Winthereik 2003). Technologies for documentation and coordination of work have co-evolved together with organizational structures, personnel's skills and work routines. The resulting collection of paper-based tools (forms, records, binders, tables, shelves etc.) and organizational routines comprises a complex information infrastructure that supports medical work (Berg 1999). This is often taken for granted, and its crucial role is often only realized when disturbances occur, e.g. when a digitization project is initiated (Vikkelsø 2005). While the embeddedness of infrastructures may be considered as a constraint for infrastructure development, Bietz et al. (2010) suggest understanding it as a resource that can be used productively as "much of the value of infrastructures lies in the relationships they embody" (Bietz et al. 2010, p.251). In their analysis of a cyberinfrastructure, Bietz et al. (2010) show how embeddedness is not only an important result of infrastructure development but also a precursor in building infrastructures.

In this paper we examine a case of such a re-infrastructuring process. Of particular concern is how existing parts of the infrastructure get re-oriented, what work this entails, and how an 
embedded infrastructure in use can be re-purposed. In addition, it is important to understand such a process in terms of design practices.

\section{Research Method}

This paper reports from a longitudinal empirical case study on eDialogue, a government eHealth initiative in Norway to develop and launch electronic health services for the exchange of information between patients and healthcare providers. We conducted this study in the context of a large-scale research program on the interplay between new information technologies (IT) and existing modes of organizing within Norwegian healthcare. The site of this study is the specialized government Agency which is authorized to implement national health policies and to ensure secure and simple information flows in the health and care sector (from now on referred as the Agency). Within the Agency, a dedicated team was engaged with the eDialogue initiative. This team included members with different competences and backgrounds (e.g. experience design, interface design, back-end development, technology architecting, legal and compliance).

This study adopts a qualitative interpretive research approach (Klein and Myers 1999; Walsham 1995) aiming to examine the phenomenon in question through the experiences of those working in the project. We approached our study by engaging in infrastructural inversion (Bowker 1994), and focusing on the activities that result to the functioning of the infrastructure (the design and development work of the project team), rather than those supported by the infrastructure (e.g. healthcare practitioner - patient communication practices). We were struck by the growing complexity of the work for eDialogue over time in terms of increased number of partners with various roles, increased coordination challenges, and also increased uncertainty on how relations would evolve over time. To understand the unfolding of changes, we combined different methods for data collection and we included document analysis, observations and semi-structured interviews in two main phases of data collection from January 2013 to December 2014. During the period January to June 2013 we assembled and reviewed a range of programmatic and strategic documents with the purpose to understand the background, context and motivation for the eDialogue initiative. A second phase of data collection took place from August 2013 to December 2014 with intensive fieldwork. In this period, the two authors attended the weekly eDialogue project meetings and took detailed notes (49 meetings). Our role was of outside observers and we were introduced to the team by the project manager as University researchers. Both authors had previously participated in research projects in the IT healthcare sector in Norway and had previous knowledge of the Norwegian healthcare context and ongoing developments. We did not ask questions during the meetings as we did not want to interrupt the flow of the discussion, but, we often asked clarification questions to single participants right after meetings. During meetings, the eDialogue team members would update each other on the progress, emerging challenges and plan for the next steps both short and long term. Additionally, we were granted access to the repository of documents maintained by the team and were offered the possibility to take part in other thematic meetings (on specific issues) and workshops. During this second phase, the two authors together also conducted a total of 28 semi-structured interviews with various team members including managers. An interview guide was prepared collaboratively for each interview, and it was used 
in a flexible way to allow following interesting threads and emerging themes. Interviews lasted approximately 1 hour each and have been recorded and fully transcribed. Interviewees were asked in their first interview to describe their role and activities in the project, their work with external partners, and the challenges they faced. Interviews were also conducted with other key persons within the eHealth Agency with roles in parallel projects or who were involved in the pre-study. The main contact person was the project manager who also facilitated contact with other informants in the Agency. In summary, the research reported is based on data collected using a combination of fieldwork and documents' analysis (Table 1).

\section{INSERT TABLE 1 ABOUT HERE}

The collected data were analyzed by focusing first on reconstructing the chronology of events and key decisions for eDialogue, from the pre-study to the point when the team started organizing and planning the pilot of the services. Our interest in infrastructuring informed the coding of our interview data and of our notes from the status and other thematic meetings. Data analysis was carried out collaboratively by the two authors in several stages. A first stage took place right after the attendance of meetings and interviews, when we would exchange our interpretations, discuss them and also plan how to proceed with the data collection. For instance, if it would be relevant to contact other informants or search for relevant documents in the archive. A second stage took place when re-creating the timeline of the events by comparing and combining the data from meeting notes, interview transcripts and archival documents. A third stage took place when writing the detailed narrative of the case with a focus on how the embeddedness of the existing infrastructure was handled in the project. We collaboratively identified relevant passages from the interviews that would better represent the interviewees' perspective. Our research did not cover the pilot phase as it was postponed to after the end of our research project, and we did no longer have access to the field site.

\section{Case Study: re-infrastructuring patient-GP interactions through eDialogue}

\subsection{Case Background}

Norway has a well-developed healthcare information infrastructure. All GP offices, hospitals and nursing homes use Electronic Patient Record systems (EPRs) (Norwegian Center for Electronic Patient Records 2011). The communication across organizations is supported by the Norwegian Health Network (NHN) which is a dedicated, closed, secure network that was established nationally in 2004. NHN was created by harmonizing and consolidating previous existing regional broadband networks, and by pursuing national standards for electronic communication in the health sector. Initially, NHN was used to connect hospitals and gradually it was expanded to GP offices, community health centres, nursing homes and recently also pharmacies. The exchange of information among healthcare providers is currently supported by standardized messages, for instance, for referrals and discharge summaries, requisitions and test results, and electronic prescriptions.

In June 2011, the Norwegian government launched the national e-health platform HealthNorway with the aim to provide a basis for the development of new electronic health 
services for patients and a single point of access to existing services. The Norwegian Government envisioned that HealthNorway will strengthen the citizen's role in healthcare by making it easier to find and choose health providers, providing access to personal health information, and by offering services of self-service and self-help. HealthNorway was initiated by the specialized governmental Agency which is authorized to implement national health policies and to ensure secure and simple information flows in the health and care sector.

The Agency kept both the ownership and the management of HealthNorway after its launch. Initially, HealthNorway offered only non-personalised quality-assured health information (on prevention and treatments, patient rights, and quality indicators for healthcare facilities) which was accessible without authentication and authorisation requirements. Soon after the initial launch, a process started to define a new strategy toward 2017 describing the vision and action plan for further development. It was agreed that the priority should be on designing new citizenoriented services in line with the main strategic political goals to "reinforce patient- and usersrole by making the everyday experience of healthcare easier and at the same time contribute to increase quality and effectiveness of health services" (quote from the strategy plan). In August 2013, the secure personalized service MyHealth was launched. By logging-in to MyHealth citizens could access personalized information retrieved from the repositories of various existing information systems (My Expenses, My GP, and My Prescriptions). Additionally, the Agency decided to develop new secure messaging services between patients and healthcare providers (later called eDialogue services).

The work for eDialogue officially started in 2012 with a preparatory study. The whole endeavor was initiated, ran and funded by the Agency. The aim of eDialogue was to support interactive services (between citizens and healthcare providers both asynchronous and synchronous), and in the long run, to cover both primary and hospital care. Primary care was prioritized so, the first step of the initiative was to enable digital communication between citizens and GPs. The outcome of the preparatory study for eDialogue was the specification of four new types of electronic services that would have to be supported: booking of appointments, renewal of prescriptions, electronic contact for administrative purposes and e-consultation. A specific project for eDialogue was launched in spring 2013. In the sections that follow we present the design and development of eDialogue as work of re-infrastructuring. First we set the stage by describing the novel aspects of the eDialogue project. Then we describe the work of reinfrastructuring in relation to three infrastructural relations: the use of EPR systems in the GPs offices, the information flow and archiving solution, and the representation of patient health information.

\subsection{Case Description}

\subsubsection{The novelty of eDialogue}

The eDialogue services were conceptualized as means for supporting patient-initiated electronically-mediated interactions between patients and healthcare providers. This was in line with the national health strategy which provided for a stronger user role. The national health plan stated: 
"we want users to know about the services and that they are meant to participate and influence. (...) Users and their relatives are experts concerning their own situations and what they can master. This resource can be utilized better in the treatment and rehabilitation of individual patients, but it is also necessary for the planning and development of the health services." (Norwegian Ministry of Health and Care Services, 2007).

The Agency that took responsibility for the design and development of eDialogue was prepared to address a complicated technical problem. In early 2013, an Agency report stated:

"the technical solution architecture that will realize eDialogue must support a complex electronic interaction between citizens and care providers. The architecture will realize synchronous and asynchronous interactions in a safe and efficient manner. For this there is a need for new solution components, message standards and integrations".

Practically, the eDialogue initiative entailed intervening in the existing information infrastructure of the GP offices to make it capable of supporting electronic interactions with patients. The plan was to extend the EPR systems already used by GPs with functionality for message exchange with patients. This required not only the development of new technological capabilities but also, engaging with a number of different actors. So, the problem was perceived not only as complicated technically but also, organizationally. For instance, the team had to orchestrate relations with multiple different private vendors in order to adapt the EPRs of the GP offices. Similarly, there was a need to establish a good collaboration with the organization that operates NHN in order to implement new messaging standards. An eDialogue team member commented:

"there is a lot of complexity to handle, it seems simple but it is not (...) there are multiple providers, 5 platforms and 4 different languages involved".

Overall, the initiative was complex because there was no self-contained system to be developed but rather, a number of interdependent capabilities had to be developed or adapted within a number of infrastructural components that were already in use. Specifically, the different EPR vendors were using different development languages for their products, the different shared components of the existing infrastructure were provided by different government entities and were based on multiple different platforms (e.g. for content management, citizen authentication).

The eDialogue initiative was not only challenged by the multiple interdependencies but also by the uncertainties that are inherent in all novelty. This was the first government initiative about designing and developing patient-oriented services for interactions with the healthcare practitioners. So, significant work had to be made in order to explore the requirements. One of the team participants said: "It is a new product, so to speak. (...) It is filling something that wasn't there". A big part of the challenge was to keep the process going while the team was exploring the needs and requirements. In other words, the eDialogue team had to bring novelty to deeply embedded components of an existing infrastructure. In the paragraphs that follow we 
are presenting key processes through which the eDialogue team worked towards reinfrastructuring.

\subsubsection{Working with the EPRs}

Norwegian GPs use EPR systems for documenting and accessing patient health information. Also, the GP EPRs are connected to the NHN secure network and are capable of supporting healthcare provider to healthcare provider electronic message exchange. The GP systems are developed and maintained by different private software companies (from now on referred as vendors). The current practice by which patients communicate with the GPs office does not involve the direct use of the EPRs. To book appointments patients call the office, during the available calling hours. Patient consultations are only performed face to face, and during or right after the consultation the GP enters notes in the EPR and uses the system to take the necessary further actions. For instance, referring patient to specialists or prescribing medications.

One of the first discussions in the project was about how to make use of the EPRs in the GP offices. It was decided to extend the existing EPRs and provide via them access to the new information exchange services. This way, there would be no need to create tailored webpages for the healthcare practitioners' side and to persuade them to introduce to their practices another technological tool. An alternative possibility which was discussed was to link to the existing private web applications for patient-GP communication that many GP offices were already using. Technically, this would have implied redirecting citizens from HealthNorway to private solutions. A participant on the pre-study said:

"it was a large discussion about could it actually be possible to use what is already in the market, and how would actually turn out for the citizens, if every solution should use their own specific system or would it be possible to for us to actually just link to that solution form the health portal and how would the user experience be in that case, and how would the security be".

The discussion led to the decision not to use the existing solutions. The main reason for rejecting this alternative was that these solutions are very diverse. They range from solid products developed by specialised companies, to home-grown makeshift web pages. Some of these solutions are simply not sound enough to be used as a basis to build upon, and security was raised as an issue to consider. For instance, the possibility to link the private services with the existing secure citizen portal was discussed. A pre-study participant said:

"we found out that for several reasons it would be complicated (...) at the legal side it would be sort of borderline, we did not really know if it could be done like that".

In addition, some of the existing solution included SMS reminder services for instance for reminding patient of appointments, and these services were considered not secure: "regarding the SMS, so much of it is not done in a proper legal way". Furthermore, this option would mean that the data generated during citizen-healthcare practitioner interactions would be distributed in these solutions. But the decision to reach out for the GP offices via the existing EPRs had its 
own downsides. It practically created the need to enrol the private software companies that developed the EPRs to the project since they would need to adjust their products. By enrolling the EPR vendors to the eDialogue project, the project team is relying on the collaboration with the vendors for the development of the GPs' interface. The interface became a responsibility of the vendors, while the Agency team kept the responsibility for developing in-house the patient side interface. The vendors configured new screens. To do so they used their understanding about GP office practices and worked with their users' panels.

The Agency prepared a high level specifications' document and asked the vendors to sign agreements for extending their EPRs to support also information exchange with patients. The problem with putting in place a contractual relationship between the Agency and the vendors was that it required prescribing up to a great extent the work that would be required from the vendors' side. A team member said:

"the vendors wanted the implementation guide before they would sign the agreement and I fully understand this of course. But the problem on our side, was that the functional side was actually just beginning to be worked out at the time (...) we had to take a lot of decisions that maybe would not be the same today, now that the functional side has done a lot of work, maybe something would have now been different."

This indicates the complexity of the work required. A big part of the challenge was not related to the technical interdependences but rather, to the complexity of a process that had to be exploratory and at the same time, specifications' driven.

The Agency team managed to put together a specifications' document that was concrete enough to be signed by third parties but also high level enough allowing room for taking initiatives. The Agency wanted to allow the vendors to do their own explorations and to capitalize on their long-lasting relationships with GP offices. The eDialogue team aimed to build a partnership type of relationship with the vendors and not to limit them to the role of mere providers. A manager from the eDialogue team explained:

"it's been so much discussion with them through the whole project. I think we are sort of synchronised at the same level (...) they have read all the user stories, they have access to the project documentation like the preparatory study".

The vendors actively contributed to the discussion and saw the new eDialogue developments within the EPRs as creating new opportunities to renegotiate and possibly strengthen or put at risk their existing relationships with the GP offices. For example, would it be possible for the GP offices to use the new eDialogue modules in the existing versions of their EPRs or they would need to upgrade to the latest commercial version? Depending on vendors' offerings the GP offices could make choices not only related to the introduction of eDialogue services but also related to the more general configuration of the EPRs in use and their choice of provider. 


\subsubsection{Working with information flows and archiving}

The information flows within the existing configuration of health services are based on the established information infrastructure which is oriented to health providers. Healthcare personnel use the EPR systems for registering patient information about health consultations, and other patient encounters in the GP offices. Prescription messages, laboratory test ordering and referrals are sent via NHN to designated recipients from the healthcare providers' side. In these flows the patient is not an active participant.

The introduction of eDialogue services makes possible for patients to register directly some of their own information and also, to receive information and act upon it. The inclusion of patients as active participants in the electronic information flows means that technical capabilities need to be in place both for creating, sending and receiving messages but also, for accessing all message exchange threads with current and past healthcare providers. From the healthcare providers' side, the messages would be sent from the EPR systems and consequently, they could be stored in the EPR systems and considered part of the patient record. However, storing them only at the EPRs would not be a good solution for ensuring reliable and continuous access to patients. First of all, GPs might switch off their computers after working hours or might have temporary network connection problems that would disrupt access to the messages exchanged. In addition, if the messages were to be stored locally in the GPs' EPR system, consolidated views across different providers would only be possible through accessing multiple local systems (this would be required for example in the case of patients that have changed GPs throughout the years). The eDialogue team identified the need for a central storage solution, provisionally named 'personal health archive', that could be available to citizens $24 / 7$ and enable them to read their messages. Hence, the re-orientation of information flows to cover patient provider exchanges also created new archiving needs.

During the early stages of the eDialogue conceptualization the archiving needs were not fully elaborated. One of the informants recalls that the idea of a personal health archive remained a vague concept that could become anything varying from "something very small, only for this project" or "potentially a key component for the platform". In addition, it was not considered a priority. An informant said:

"we needed some kind of storage and that was not the biggest deal, there were so many other things around the dialogue process, the security, and how to operate the different work processes of the doctors, and this storing of some small pieces of information, which is not much, it is not very complicated, it did not get much attention, we just needed a database".

In August 2013, work on specifying the requirements for the archive started. Initially, the team considered to develop a tailored solution in-house. However, this option was discarded due to scalability concerns. As the work on specifications gradually evolved throughout autumn, it was realized that the archive would have to fulfil two needs: provide storage to cater for eDialogue and also provide a versatile storage component for possible future usages related to other not-yet-defined services. This second aim was considered important and of strategic nature. 
The team envisioned that in the future it would be possible to store in the archive messages from the hospitals including heavy files from picture archiving and communication systems and extracts from records. A team member explained:

"When you have the health archive at least you are in control of documents and the storage. You could create different views for the users when they log in based on what is in the archive creating a reliable and expandable storage solution".

So gradually, the project team realised that there was a great potential for future developments based on the archive, as one of the informants explained:

"maybe, we do not know, maybe the archive will have an important role, it will be the place where you take information from one part of the health service and send it to another (...) potentially we talk of terabytes and petabytes, so it is big, if this is widely used it will probably be in a few years the biggest database in Norway".

The project team recognized that the archive could become a central piece in the Norwegian Healthcare information infrastructure, and that this decision would have long-term consequences for the whole infrastructure.

The inclusion of patients in the data flows meant that they would need to be provided with technical capabilities to store and manipulate data from a wide variety of healthcare applications. These considerations led to the decision to procure a fully-fledged storage solution. An informant explained:

"a standard solution is giving us quite a few things, it is stable, it is well proven so we know it works, it has been handling huge databases for other customers around the world, so we know is capable of taking this amount of data, it is of course secure, it has very good support for security within the solution, and all the kind of basic services you need like putting in documents, deleting, changing who can access a document, logging everything that is happening, all these are kind of standard".

This was a major decision for the initiative as explained by a manager: "I think that was a big turning point (...) it expanded the scope. It turned into something else than we originally thought". The patient archive would be a new patient-controlled component in the overall healthcare information infrastructure. Being something brand new and not an adaptation of existing capabilities, led the team to consider it as straightforward and simple at the beginning. Nevertheless, it soon turned out that even though the archive was a new addition, it would have to replicate key characteristics (e.g. for data structuring, security, action traceability) from most of the existing provider-controlled archives. 


\subsubsection{Working with new representations of patient health information}

Orienting information from several existing healthcare provider systems towards the patients and allowing patients to directly send information to these systems created the need of introducing a suitable interface for the patient side. This interface was designed and developed by the Agency. The eDialogue team started to discuss how messages would be presented, and according to which logic they should be organized in order to facilitate the new patient role. The design team turned to the potential users investigating their needs and preferences. An informant explained how the expressed interests of the patients inspired different design solutions for the representation and ordering of information:

“when I say ok so 'what does the patient want?' and they say 'they are very much into choose and book", then maybe the calendar should be the focal point when you log in. So I am kind of always thinking what is the core page instead of just thinking each functionality by itself, what is the focal point, the core page, the two three most important core pages in this solution".

As explained, the team was not only searching for a design solution for the patient interface but also for the underlying concept - the chronological order of a calendar for instance - for making the various elements hang together coherently.

One main difficulty faced during the conceptualization of the patient-side information representations was the overall uncertainty about the future functionality and services to be developed in the context of HealthNorway. The eDialogue team was the first to work on the design of novel functionality for national level patient-provider interactions, but they knew that other projects would also start soon and that the aim was to develop a comprehensive set of services covering interactions with the whole healthcare sector. For instance, although the first step was to develop services for patient interactions with primary care (GP offices), it was also decided that additional services for interactions with the hospitals would soon be introduced. Hence, it was important not to use as a sole basis for the design concept the GP related services. One suggestion for how to solve this problem, was based on the experience from Denmark and the design of the Danish healthcare platform Sundhed.dk. However, the Danish concept was different because it was used as an interface for both patients and healthcare providers. An informant explained:

"we have been looking a lot at Denmark and sundhed.dk, which is doing a lot of the things that we are doing today but they have chosen different things, they have two very separate entrances for the health specialists, and for the citizens (...) we don't want to do that, we want all the content laying in one big pool and then tag it, and then saying that you should gain access to the information in terms of what you want to know".

As a solution, the concept of 'timeline' was suggested because it is scalable and flexible to work with. A team member said:

"we think that what the users will be most interested in now and in the future is "your timeline" and your timeline will be your appointments with the doctor, if you think 
about Facebook and how that works, here is an appointment that is generated from the system here is an event that you put in yourself because maybe you were out travelling and you broke your ankle in New York city, but you want it to be part of your timeline, so something will be generated from the system, and something you will put in yourself'.

Existing representations provided by social media inspired the conceptualization of the patient side interface but, also, the timeline idea was a good way to exploit the fact that all the different data elements (including elements that were not currently defined) would have time-related properties. Actually, the organization of health records according to the temporal sequence is one of the most common organization approaches within healthcare.

Furthermore, the idea of providing the patients with search-driven options for delimiting and focusing the views of their personal health information was added. An informant clarified:

"with the search you can say 'show me all the incidents with the GP' or 'show me all the discharge letters' so it will be possible to see in the context of time and also in the context of the content."

The combination of search and timeline was thought to be a powerful way of providing information views that would be fully controlled by the patients:

"so we think that search will be very important, it will be $100 \%$ search-driven, (...), and the timeline is scalable, you can build it and build it, and now we have GPs and soon specialists, but what about your dentist, and your chiropractor, and all the others that want to play with us as well".

The combination of time-based ordering and search-driven data selection is generic enough to accommodate all types of data and can work both at the beginning when the data available will be limited and also, later on when significant volumes of data might be available. An informant stated that "this vision is the most scalable, useful, interesting to go right now." Scalability was recognized as a core critical dimension also for the patient-side interface. The team involved in the design of the patient-side interface had to come up with a concept to provide comprehensive views to the growing volumes of health-related information from different, specialized, healthcare provider systems. The patient-side would need to handle the growing volumes and the great diversity of data. An informant said:

"there are so many things to be aware of in this process we cannot paint ourselves in the corner, like our main airport, it was too small the day it was open, and we do not want to be there, we want a good concept that we believe in and can grow and grow without losing itself."

Overall, the team engaged in the design of the patient oriented health information representations had to prepare for underspecified future use by the patients. This entailed thinking of how to accommodate all types of information currently stored within the diverse healthcare providers' systems and also, new types of information that could potentially be generated or simply linked to the infrastructure by the patients themselves. 


\section{Discussion}

In this section, we elaborate on the concept of re-infrastructuring as a particular type of engagement with an information infrastructure. Specifically, re-infrastructuring indicates the introduction of capabilities to facilitate new logics in a mature infrastructure by leveraging established relationships. First, we explain what re-infrastructuring involves and how it can enrich a processual perspective on infrastructures (Section 5.1) and then, we identify design concerns that are specific to attempting "turns" in an infrastructure's evolution (Section 5.2). By articulating the distinctiveness of re-infrastructuring and drawing attention to its characteristics we aim to highlight the variable dynamics of infrastructuring processes and the importance of acknowledging them.

\subsection{Re-infrastructuring: working with embeddedness as a resource}

Pollock and Williams advocate a biography of artifacts' perspective for researching information infrastructures (Pollock and Williams 2010). Such a perspective entails an understanding of the different potentialities of intervening in an infrastructure at different moments, locales and nexuses throughout its life. Prior research has investigated infrastructuring as an intentional ongoing activity for creating, sustaining and transforming infrastructures (e.g. Bietz et al. 2010; Bossen and Markussen 2010; Karasti and Baker 2004; Parmiggiani et al. 2015; Pipek and Wulf 2009). This research investigated diverse occasions of infrastructuring varying from early-stage ordering activities through the introduction of new systems for coordination among distributed actors, to maintenance and enhancement activities within established infrastructural arrangements and to repurposing activities for capabilities already in place. Although this prior research covered different potentialities and different concerns related to different infrastructuring occasions, these differences were not brought into attention and infrastructuring remains an undiscerning, all-inclusive term.

The case we studied is about a particular occasion of infrastructuring. For this, we use the term 're-infrastructuring' to signify the activities for facilitating new logics when social and technological networks with long reaches are already in place and are leveraged for the instigation of novelty. We studied the eDialogue project as an instance of re-infrastructuring as it brought a new turn in the life of the Norwegian eHealth infrastructure. Earlier initiatives aimed to add a layer upon the mature provider-oriented healthcare information infrastructure and complement it by developing additional components for patients' electronic access to their personal health information. This type of service (electronic access to existing documentation) only requires one-way information flows (from the healthcare provider's side towards the patients). Hence, it entails minimal reconfiguration of the existing provider's side arrangements. With the launch of the eDialogue project, two-way information exchange had to be enabled. This entailed tweaking the existing technologies in place and triggering changes to established healthcare providers' practices. The actors involved in the initiative had to engage with the whole spectrum of the existing information infrastructure in order to orient it toward the patients. Specifically, they had to purposefully introduce new technological capabilities that afford connections to what is already in place, mobilizing and recombining pre-existing resources, blending novelty in the already dense technology landscapes of healthcare. The 
eDialogue project members aimed to facilitate a new role for the patients drawing on the embeddedness of the existing eHealth infrastructure, using it as a resource (Bietz et al. 2010).

Embeddedness was demonstrated in the interconnectedness and ubiquity of the existing infrastructure. These were acknowledged as accomplishments to be retained and leveraged not as obstructions to novelty. Specifically, the team involved in the design of the eDialogue services made use of the embeddedness of the EPRs. Patient record systems are intimately intertwined with organizational structures and work practices of the GPs (Berg and Winthereik 2003). Embeddedness was seen as a quality that made the installed base of the EPR system a strong base to build on. The team opted for using embeddedness as a resource and embeddedness became 'someone's work or problem' (Star 1999). Maintaining embeddedness would facilitate quick deployment and circumnavigate the bootstrapping problem but required engaging the EPR vendors in the design and development process, and dealing with their different systems and different work practices. Interestingly, the maintenance of embeddedness, was a concern that shaped all team activities beyond the ones that relate to adaptations to existing components. For instance, it shaped the approach followed for the patient archive. Although the archive is something brand new and not an adaptation of existing capabilities, the team could not address it independently. The new archive had to accommodate the scale of the existing infrastructure and the data handling requirements of the existing provider-controlled archives.

The articulation of re-infrastructuring as a particular occasion of infrastructuring, brings into attention the different turns in the life of an infrastructure. This can be useful for methodological purposes (to help researchers in making decisions about when and how to study infrastructures). Furthermore, it suggests the need for making distinctions related to infrastructures' evolutionary trajectories in order to capture specific issues and provide insights on how to address them. Prior research has pointed to infrastructuring challenges without relating them to specific stages within an infrastructure's evolution. For instance, Hanseth and Lyytinen pointed to the problems of bootstrapping and adaptability (Hanseth and Lyytinen 2010), Karasti et al. pointed to the problem of reconciling different temporal orientations i.e. project time and infrastructure time (Karasti et al. 2010), Pipek and Wulf pointed to the challenges of setting boundaries by renegotiating what remains the same and what is changed, by whom ('professional designers' or other stakeholders including users) and when (before or during use) (Pipek and Wulf 2009). The overall insights about infrastructuring contributed to developing a better understanding about these processes and produced a significant body of knowledge. Nevertheless, as Pollock and Williams suggest, the location within the overall 'historical arc' of an infrastructure's evolution matters when discussing design related challenges (Pollock and Williams 2010) and needs to be further researched. For example, the early stages of the evolution of an information infrastructure may allow more openness than later stages when existing commitments and alignments reduce the available options. In the section that follows we present the design concerns of re-infrastructuring that were identified in the analysis of our case.

\subsection{Design concerns of re-infrastructuring}


Re-infrastructuring is challenging as it entails building on the installed base and transforming it at the same time (Aanestad et al. 2017). This creates a paradox: new developments need to fit and make use of existing arrangements and at the same time transform them. Overfitting on the existing installed base may strengthen its irreversibility and hinder change, disregarding it may limit the initial utility of any initiative and impede growth (Henningsson and Hanseth 2011). Furthermore, staying too close to existing logics can undermine the change agenda but moving too far increases the risk of harming the fragile balance of what is in place by adding new actors or purposes (Langhoff et al. 2016). Addressing embeddedness as a resource can be a basis "for creative design and innovation or a trap from which it is difficult to escape" (Lanzara 2014). Healthcare is a domain where re-infrastructuring is especially challenging because the technological landscapes are dense (a lot of existing digital capabilities are already in place) and, they tend to consist of multiple semi-autonomous parts (Bygstad et al. 2015; Pinelle and Gutwin 2006; Pollock and Williams 2010).

Re-infrastructuring is a strategically directed process, change is coming through purposeful interventions not as pure organic, bottom-up evolution. In our case, the work of reinfrastructuring was not driven by locally initiated tailoring, appropriation, or repair interventions, rather it was policy-driven. Nevertheless, although the Agency is a national actor with significant power (in terms of resources and institutional influence) that works with a specific agenda for change, there is also a multitude of other actors that take action and influence the evolution of the infrastructure. Hence, the new features of the infrastructure emerge from the meeting between a strong actor's intentionality with the numerous micro-level decisions and actions by a multitude of related actors. This resonates with Star's argument about infrastructures never being changed from above, and nobody being really in charge of them as multiple negotiations and adjustments are involved (Star 1999). Previous studies on infrastructuring have pointed to the importance of creating synergies, aligning interests and goals, motivating cooperation (Bietz et al. 2010; Pennington 2011; Procter et al. 2011; Spencer et al. 2011). All these are important for re-infrastructuring but what is a particular feature for this specific type of infrastructure activities is the breadth and multitude of actors involved. Reinfrastructuring entails grappling with the scope and scale of a fully-fledged infrastructure that is already in place. Purposeful interventions in an existing infrastructure entail an engagement with the intentionality of various actors as development decisions are distributed within the network of existing technologies, people and organizations (Vassilakopoulou et al. 2016). Traditional design approaches are challenged by the distributed character of design for reinfrastructuring and the complexity of cooperation within an evolving constellation of multiple actors (Grisot and Vassilakopoulou 2015b).

To answer our research question, the work entailed in re-infrastructuring revolves around addressing the two key design-related concerns identified: a) bringing novelty without being trapped in the existing arrangements or harming what is in place, b) bringing changes that are within a specific direction although they happen through distributed decision taking. Our case shows how a concern for balancing novelty with continuity led to specific choices for working with the EPRs, for specifying the archiving needs and for conceptualizing how to represent and visualize patient health information. Furthermore, our case suggests the need for finding ways 
to support a two-faced process which is strategically directed but relies on distributed decision making.

\section{Conclusion}

With this paper we aim to extend the conceptualizations of infrastructuring by suggesting a more explicit acknowledgment of the different stages in infrastructural evolution. We contribute towards this direction with our research which has a specific focus on the work entailed in dealing with turns in infrastructure development. We have used the term reinfrastructuring to signify the activities for facilitating new logics when social and technological networks with long reaches are already in place and are leveraged for the instigation of novelty. Investigating the challenges of re-infrastructuring is especially relevant to the ongoing patientoriented movement within healthcare (Wilson and Strong 2014). The re-orientation of existing infrastructural arrangements towards the patients is an effort that aims to reconfigure the inner workings of healthcare. Our case shows how breaking away from simply overlaying new capabilities upon a pre-existing stratum (David 1990) involves reconfiguring also the preexisting arrangements and productively using embeddedness as an accomplishment to be retained and as a resource to leverage (Bietz et al. 2010). To better understand this specific process of infrastructuring we have identified two design concerns which draw attention to the complexity of design interventions in the context of large-scale and well established infrastructures.

\section{Acknowledgments}

We acknowledge the support of the Responsive Architectures for Innovation in Collaborative Healthcare Services (REACH) project, funded by Norwegian Research Council, VERDIKT program (project nr. 213143), and of the C3 Center for Research-based Innovation funded by the Norwegian Research Council (project nr. 237766). We are grateful to the members of the team working on eDialogue who participated in the study, and to the anonymous reviewers for helping us improve the paper.

\section{References}

Aanestad, Margunn, Miria Grisot, Ole Hanseth, and Polyxeni Vassilakopoulou (eds) (2017). Information Infrastructures within European Health Care: Working with the Installed Base. London: Springer.

Anderson, Stuart, Gillian Hardstone, Rob Procter, and Robin Williams (2008). Down in the (data) base (ment): Supporting configuration in organizational information systems. In M. S. Ackerman, C. A. Halverson, T. Erickson and W. A. Kellogg (eds): Resources, co-evolution and artifacts. London: Springer, pp. 221-253.

Baker, Karen S. and Florence Millerand (2010). Infrastructuring ecology: Challenges in achieving data sharing. In J. N. Parker, N. Vermeulen and B. Penders (eds): Collaboration in the New Life Sciences. Farnham, England: Ashgate, pp. 111-138. 
Berg, Marc (1999). Accumulating and coordinating: occasions for information technologies in medical work. Computer Supported Cooperative Work (CSCW): An International Journal, vol. 8, no. 4, pp. 373-401.

Berg, Marc and Britt R. Winthereik (2003). Waiting for Godot. In M. Berg (ed): Health Information Management: Integrating information and communication technology in health care work. New York, NY: Routledge.

Bietz, Matthew J, Eric Baumer, and Charlotte Lee. (2010). Synergizing in cyberinfrastructure development. Computer Supported Cooperative Work (CSCW): An International Journal, vol. 19, no. 3-4, pp. 245-281.

Bjørn, Pernille and Finn Kensing (2013). Special issue on information infrastructures for healthcare: The global and local relation. International Journal of Medical Informatics, vol. 82, no. 5, pp. 281-282.

Bossen, Claus and Randi Markussen (2010). Infrastructuring and ordering devices in health care: Medication plans and practices on a hospital ward. Computer Supported Cooperative Work (CSCW): An International Journal, vol. 19, no. 6, pp. 615-637.

Bowker, Geoffrey C. (1994). Science on the run: Information management and industrial geophysics at Schlumberger, 1920-1940. Cambridge, MA: MIT press.

Bowker, Geoffrey C., Karen S. Baker, Florence Millerand, and David Ribes (2009). Toward information infrastructure studies: Ways of knowing in a networked environment. In J. Hunsinger, L. Klastrup, M. Allen (eds): International Handbook of Internet Research. Springer, pp. 97-117.

Bowker, Geoffrey C. and Susan L. Star (1999). Sorting things out: classification and its consequences. Cambridge, MA: MIT Press.

Bygstad, Bendik, Ole Hanseth, and Dan Truong Le (2015). From IT Silos to Integrated Solutions. A Study in E-Health Complexity. In J. Becker, J. vom Brocke and M. de Marco (eds): Proceedings of the 23rd European Conference on Information Systems (ECIS), Münster, Germany, 26-29 May 2015.

Ciborra, Claudio U. (1997). De profundis? Deconstructing the concept of strategic alignment. Scandinavian Journal of Information Systems, vol. 9, no. 1, pp. 2.

David, Paul A. (1990). The dynamo and the computer: an historical perspective on the modern productivity paradox. The American Economic Review, vol. 80, no. 2, pp. 355-361.

de la Flor, Grace, Marina Jirotka, Paul Luff, John Pybus, and Ruth Kirkham (2010). Transforming Scholarly Practice: Embedding Technological Interventions to Support the Collaborative Analysis of Ancient Texts. Computer Supported Cooperative Work (CSCW): An International Journal, vol. 19, no. 3-4, pp. 309-334.

Edwards, Paul N. (2003). Infrastructure and Modernity: Force, time, and social organization in the history of sociotechnical systems. In T. Misa, P. Brey and A. Feenberg (eds): Modernity and Technology. Cambridge, MA: MIT Press.

Edwards, Paul N., Geoffrey C. Bowker, Steven J. Jackson, and Robin Williams (2009). Introduction: an agenda for infrastructure studies. Journal of the Association for Information Systems, vol. 10, no. 5 , pp. 6 .

Edwards, Paul N., Steven Jackson, Geoffrey C. Bowker, and Cory P. Knobel (2007). Understanding Infrastructure: Dynamics, Tensions, and Design. Report of a Workshop on History \& Theory of Infrastructure: Lessons for New Scientific Cyberinfrastructures, University of Michigan School of Information, January 2007.

Ellingsen, Gunnar and Eric Monteiro (2003). A patchwork planet integration and cooperation in hospitals. Computer Supported Cooperative Work (CSCW): An International Journal, vol. 12, no. 1, pp. 71-95.

Ellingsen, Gunnar and Eric Monteiro (2006). Seamless integration: standardisation across multiple local settings. Computer Supported Cooperative Work (CSCW): An International Journal, vol. 15, no. 5-6, pp. 443-466.

Ellingsen, Gunnar and Kristoffer Røed (2010). The role of integration in health-based information infrastructures. Computer Supported Cooperative Work (CSCW): An International Journal, vol. 19 , no. 6, pp. 557-584.

Farrell, Joseph and Garth Saloner (1986). Installed base and compatibility: Innovation, product preannouncements, and predation. The American economic review, vol. 76, no. 5, pp. 940-955. 
Grisot, Miria, Ole Hanseth, and Anne Thorseng (2014). Innovation of, in, on infrastructures: articulating the role of architecture in information infrastructure evolution. Journal of the Association for Information Systems, vol. 15, no. 4, pp. 197-219.

Grisot, Miria and Polyxeni Vassilakopoulou (2011). Challenges in institutionalising electronic platforms for patient-healthcare provider communication. International Journal of Electronic Healthcare, vol. 6 , no. $2 / 3 / 4$, pp. $138-152$.

Grisot, Miria and Polyxeni Vassilakopoulou (2013). Infrastructures in healthcare: The interplay between generativity and standardization. International Journal of Medical Informatics, vol. 82, no. 5, pp. 170-179.

Grisot, Miria and Polyxeni Vassilakopoulou (2015a). Creating a National E-Health Infrastructure: The Challenge of the Installed Base. In J. Becker, J. vom Brocke and M. de Marco (eds): Proceedings of the 23rd European Conference on Information Systems (ECIS), Münster, Germany, 26-29 May 2015.

Grisot, Miria and Polyxeni Vassilakopoulou (2015b). The Work of Infrastructuring: A Study of a National eHealth Project. In N. Boulus-Rødje, G. Ellingsen, T. Bratteteig, M. Aanestad, M., and P. Bjorn (eds): Proceedings of the 14th European Conference on Computer Supported Cooperative Work (ECSCW), 19-23 September 2015, Oslo, Norway, Springer, pp.205-221.

Hanseth, Ole and Margunn Aanestad (2003). Design as bootstrapping. On the evolution of ICT networks in health care. Methods of Information in Medicine, vol. 42, no. 4, pp. 385-391.

Hanseth, Ole, Edoardo Jacucci, Miria Grisot, and Margunn Aanestad (2006). Reflexive Standardization: Side effects and complexity in standard making. MIS Quarterly, vol. 30, Special Issue on Standard Making, August 2006, pp. 563-581.

Hanseth, Ole and Nina Lundberg (2001). Designing work oriented infrastructures. Computer Supported Cooperative Work (CSCW): An International Journal, vol. 10, no. 3, pp. 347-372.

Hanseth, Ole and Kalle Lyytinen (2010). Design theory for dynamic complexity in information infrastructures: the case of building internet. Journal of Information Technology, vol. 25, no. 1, pp. 1-19.

Hanseth, Ole and Eric Monteiro (1998). Changing irreversible networks. In W. Baets (ed): Proceedings of the Sixth European Conference on Information Systems (ECIS), 4-6 June, Aix en Provence, France.

Henningsson, Stefan and Ole Hanseth (2011). The essential dynamics of information infrastructures. In C. Beath, M. D. Myers, and K. K.Wei (eds): Proceedings of International Conference of Information Systems (ICIS), 4-7 December, Shanghai, China.

Hepsø, Vidar, Eric Monteiro, and Knut H. Rolland (2009). Ecologies of e-Infrastructures. Journal of the Association for Information Systems, vol. 10, no. 5, pp. 430-446.

Jackson, Steven (2014). Rethinking Repair. In T. Gillespie, P. Boczkowski and K. Foot (eds): Media technologies: Essays on communication, materiality, and society. Cambridge, MA: MIT Press, pp. 221-240.

Jackson, Steven, Alex Pompe, and Gabriel Krieshok (2012). Repair worlds: maintenance, repair, and ICT for development in rural Namibia. In S. Poltrock and C. Simone (eds): Proceedings of the ACM 2012 conference on Computer Supported Cooperative Work CSCW'12, February 11-15, 2012, Seattle, Washington, USA.

Karasti, Helena and Karen S. Baker (2004). Infrastructuring for the long-term: Ecological information management., 2004. In: Proceedings of the 37th Annual Hawaii International Conference on System Sciences (HICSS), 5-8 January 2004, Hawaii, USA.

Karasti, Helena, Karen S.Baker, and Florence Millerand (2010). Infrastructure time: Long-term matters in collaborative development. Computer Supported Cooperative Work (CSCW): An International Journal, vol. 19, no. 3-4, pp. 377-415.

Karasti, Helena and Anna-Liisa Syrjänen (2004). Artful infrastructuring in two cases of community PD. In: A. Clement, F.d. Cindio, A.-M. Oostveen, D. Schuler and P.v.d. Besselaar (eds): Proceedings of the 8th biennial Participatory Design Conference, PDC 2004, Toronto, Canada, July 27-31, Volume 1, New York, NY: ACM, pp.20-30.

Klein, Heinz K. and Michael D. Myers (1999). A set of principles for conducting and evaluating interpretive field studies in information systems. MIS Quarterly, vol. 23, no. 1, pp. 67-93. 
Langhoff, Tue, Mikkel H. Amstrup, Peter Mørck, and Pernille Bjørn (2016). Infrastructures for healthcare: From synergy to reverse synergy. Health Informatics Journal, First Published July 25, 2016.

Lanzara, Giovan Francesco (2014). The Circulation of Agency in Judicial Proceedings: Designing for Interoperability and Complexity. In F.Contini and G.F. Lanzara (eds): The Circulation of Agency in E-Justice: Springer, pp. 3-32.

Monteiro, Eric (1998). Scaling information infrastructure: The case of next-generation IP in the Internet. The Information Society, vol. 14, no. 3, pp. 229-245.

Monteiro, Eric, Neil Pollock, Ole Hanseth and Robin Williams (2013). From artefacts to infrastructures. Computer Supported Cooperative Work (CSCW): An International Journal, vol. 22, no. 4-6, pp. 575-607.

Neumann, Laura J. and Susan L. Star (1996). Making infrastructure: The dream of a common language. In J. Blomberg, F. Kensing and E. Dykstra-Erickson (eds): Proceedings of the 4th biennial Participatory Design Conference PDC 1996, Cambridge, MA, USA, 13-15 November 1996, Palo Alto, CA, USA.

Norwegian Center for Electronic Patient Records. (2011). EPJ Monitor 2010: Oversikt over utbredelse og klinisk bruk av IKT $i$ helsetjenesten (Overview of prevalence and clinical use of ICT in health services). http://hiwiki.idi.ntnu.no/images/c/c5/EPJ-monitor-2010-v1.2.pdf

Norwegian Ministry of Health and Care Services (2007). National Health Plan for Norway (2007-2010) http://www.regjeringen.no/upload/HOD/National_health_plan_eng_06052007.pdf

Norwegian Ministry of Health and Care Services (2012). Stortingsmelding $n r$. 9: Én innbygger - én journal. Digitale tjenester $i$ helse- og omsorgssektoren.

Norwegian Ministry of Health and Care Services. (2014). HelseOmsorg21: A knowledge system for improving public health. National Research and Innovation Strategy for Health and Care http://www.forskningsradet.no/prognett-helseomsorg21/Forside/1253985487298

Parmiggiani, Elena, Eric Monteiro, and Vidar Hepsø (2015). The Digital Coral: Infrastructuring Environmental Monitoring. Computer Supported Cooperative Work (CSCW): An International Journal, vol. 24, no. 5, pp. 423-460.

Pennington, Deana (2011). Bridging the disciplinary divide: Co-creating research ideas in escience teams. Computer Supported Cooperative Work (CSCW): An International Journal, vol. 20, no. 3, pp. 165-196.

Pinelle, David and Carl Gutwin (2006). Loose coupling and healthcare organizations: deployment strategies for groupware. Computer Supported Cooperative Work (CSCW): An International Journal, vol. 15, no. 5-6, pp. 537-572.

Pipek, Volkmar and Volker Wulf (2009). Infrastructuring: Toward an Integrated Perspective on the Design and Use of Information Technology. Journal of the Association for Information Systems, vol. 10 , no. 5 , pp. 447-473.

Pollock, Neil and Robin Williams (2010). E-infrastructures: How do we know and understand them? Strategic ethnography and the biography of artefacts. Computer Supported Cooperative Work (CSCW): An International Journal, vol. 19, no. 6, pp. 521-556.

Procter, Rob, Mark Rouncefield, Meik Poschen, Yuwei Lin and Alex Voss (2011). Agile project management: a case study of a virtual research environment development project. Computer Supported Cooperative Work (CSCW): An International Journal, vol. 20, no. 3, pp. 197-225.

Ribes, David and Geoffrey C. Bowker (2009). Between meaning and machine: Learning to represent the knowledge of communities. Information and Organization, vol. 19, no. 4, pp. 199-217.

Ribes, David and Thomas A. Finholt (2009). The Long Now of Technology Infrastructure: Articulating Tensions in Development. Journal of the Association for Information Systems, vol. 10, no. 5, pp. 375-398.

Ribes, David and Jessica B. Polk (2014). Flexibility relative to what? Change to research infrastructure. Journal of the Association for Information Systems, vol. 15, no. 5, pp. 287-305.

Rolland, Knut H. and Eric Monteiro (2002). Balancing the local and the global in infrastructural information systems. Information Society, vol. 18, no. 2, pp. 87-100.

Sahay, Sundeep, Eric Monteiro, and Margunn Aanestad (2009). Configurable politics and asymmetric integration: Health e-infrastructures in India. Journal of the Association for Information Systems, vol. 10, no. 5, pp. 399-414. 
Schilling, Melissa A. (1999). Winning the standards race:: Building installed base and the availability of complementary goods. European Management Journal, vol. 17, no. 3, pp. 265-274.

Spencer, Dimitrina, Ann S. Zimmerman, and David Abramson (2011). Special theme: project management in e-science: challenges and opportunities. Computer Supported Cooperative Work (CSCW): An International Journal, vol. 20, no. 3, pp. 155-163.

Star, Susan L. (1999). The ethnography of infrastructure. American Behavioral Scientist,vol. 43, no. 3, pp. 377-391.

Star, Susan L. and Karen Ruhleder (1996). Steps toward an ecology of infrastructure: Design and access for large information spaces. Information Systems Research, vol. 7, no. 1, pp. 111-134.

Vassilakopoulou, Polyxeni, Miria Grisot, and Margunn Aanestad (2016). Enabling Electronic Interactions between Patients and Healthcare Providers: a service design perspective. Scandinavian Journal of Information Systems, vol. 28, no. 1, pp. 71-90.

Vikkelsø, Signe (2005). Subtle redistribution of work, attention and risks: Electronic patient records and organisational consequences. Scandinavian Journal of Information Systems, vol. 17, no. 1, pp. 10.

Walsham, Geoff (1995). Interpretive Case Studies in IS Research: Nature and Method. European Journal of Information Systems, vol. 4, no. 2, pp. 74-81.

Wilson, E. Vance and Diane M. Strong (2014). Editors' Introduction to the Special Section on Patientcentered e-Health: Research Opportunities and Challenges. Communications of the Association for Information Systems, vol. 34, no. 1, pp. 323-336.

Zimmerman, Ann S. (2008). New knowledge from old data the role of standards in the sharing and reuse of ecological data. Science, Technology \& Human Values, vol. 33, no. 5, pp. 631-652.

Zimmerman, Ann S. and Thomas A. Finholt (2007). Growing an infrastructure: The role of gateway organizations in cultivating new communities of users. In T. Gross and K. Inkpen (eds): Proceedings of the 2007 international ACM conference on Supporting Group Work, GROUP'07, Sanibel Island, Florida, USA, November 4-7, 2007, pp.239-248.

Table 1. Data Sources.

\begin{tabular}{l|l} 
Source & Description \\
\hline $\begin{array}{l}\text { Interviews } \\
\begin{array}{l}\text { Observations during } \\
\text { weekly } \\
\text { workshops and thematic } \\
\text { meetings }\end{array}\end{array}$ & $\begin{array}{l}49 \text { weekly meetings (status meetings with the presence of the whole team, } \\
\text { standard duration of } 60 \text { minutes each). Detailed notes taken. }\end{array}$ \\
\hline $\begin{array}{l}1 \text { design workshop (full day) } \\
\text { Document analysis }\end{array}$ & $\begin{array}{l}\text { Phase 1: Norwegian Healthcare Strategic Planning Documents; Policy, } \\
\text { Regulation and Standards Documents; }\end{array}$ \\
\hline $\begin{array}{l}\text { Phase 2: Project documents (reviewed preparatory meeting documents, } \\
\text { presentation slides, reports, and project deliverables) }\end{array}$
\end{tabular}

